http://dx.doi.org/10.18675/1981-8106.vol25.n49.p357-373

\title{
Mediação de conflitos na escola: possibilidades para o desenvolvimento moral?
}

\section{Conflict mediation in school: possibilities to moral development?}

\section{Mediación de conflictos en la escuela: ¿posibilidades para el desarrollo moral?}

\author{
Yeda Strada Raab' \\ Camila Santos Dias" \\ 'Universidade Metodista de Piracicaba (Unimep), Piracicaba, São Paulo - Brasil. E-mail: \\ yedastrada@gmail.com \\ "Fundação Hermínio Ometto (FHO|UNIARARAS), Araras, São Paulo - Brasil. E-mail: \\ camilasandias@gmail.com
}

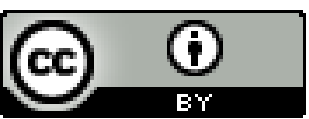

Educação: teoria e prática, Rio Claro, SP, Brasil - eISSN: 1981-8106

Está licenciada sob Licença Creative Common

\section{Resumo}

No intuito de atuar com foco nos conflitos existentes no ambiente escolar, o Estado de São Paulo tem contado com a inserção do Professor Mediador Escolar e Comunitário. Pensando na recente implementação desse profissional, esta pesquisa objetivou refletir sobre a possibilidade de o trabalho com a mediação de conflitos, na escola, auxiliar o desenvolvimento moral dos alunos. Para tanto, a metodologia empregada foi qualitativa descritiva, utilizando-se de levantamento de dados, entrevistando-se oito participantes, sendo duas professoras mediadoras escolares e comunitárias, duas professoras e quatro alunos. Os resultados foram analisados à luz da Análise de Conteúdo; tais resultados refletem a compreensão dos participantes acerca da mediação e de como esta vem sendo desenvolvida no contexto escolar, como também o que se entende por desenvolvimento moral. Acredita-se que pesquisas, nessa área, possam auxiliar na avaliação do trabalho desenvolvido, bem como no desenvolvimento dessas propostas. Pode-se observar que os profissionais de educação se sentem inseguros frente aos conflitos interpessoais, tendendo a evitá-los e não a vislumbrá-los enquanto possibilidade de aprendizado e desenvolvimento. 
Palavras-chave: Mediação; Conflitos; Educação; Desenvolvimento moral.

\begin{abstract}
In order to act with focus on conflicts in the school environment, the state of São Paulo has relied on the inclusion of School and Community Mediator Teacher. Thinking about the recent implementation of these teachers, this research aimed to discuss the possibility of working with conflict mediation assist in students'moral development. Therefore, the methodology used was qualitative descriptive, using survey data, interviewing eight participants, including two School and Community Mediator Teachers, two teachers and four students. The results were analyzed based on content analysis; these results reflect the understanding of the participants about mediation and how it is being developed in the school context, as well as what is understood as moral development. It is believed that research in this area may assist in the evaluation of their work, as well as in the development of these proposals. It can be observed that education professionals feel insecure against interpersonal conflicts, tending to avoid them and not to face them as a possibility for learning and development.
\end{abstract}

Keywords: Mediation; Conflict; Education; Moral development.

\title{
Resumen
}

Con el intuito de actuar con foco en los conflictos existentes en el ambiente escolar, el Estado de São Paulo ha contado con la inserción del Profesor Mediador Escolar y Comunitario. Pensando en la reciente implementación de ese profesional, esta investigación tuvo como objetivo reflexionar sobre la posibilidad del trabajo con la mediación de conflictos, en la escuela, auxiliar al desarrollo moral de los alumnos. Para esto, la metodología empleada fue cualitativa descriptiva, utilizando el levantamiento de datos, entrevistando a ocho participantes, siendo dos profesoras mediadoras escolares y comunitarias, dos profesoras y cuatro alumnos. Los resultados fueron analizados bajo la luz del Análisis de Contenido; tales resultados reflejan la comprensión de los participantes acerca de la mediación y de cómo esta viene desarrollándose en el contexto escolar, así como también qué se entiende por desarrollo moral. Se cree que las investigaciones, en esta área, puedan auxiliar en la evaluación del trabajo desarrollado, así como en el desarrollo de estas propuestas. Se puede observar que los profesionales de educación se sienten inseguros frente a los conflictos interpersonales, tendiendo a evitarlos y no a vislumbrarlos como posibilidad de aprendizaje y desarrollo.

Palabras clave: Mediación; Conflictos; Educación; Desarrollo moral. 


\section{Introdução}

O Sistema de Proteção Escolar (SPEC), instituído pela Resolução SE nº7/2012, refere-se a um conjunto de ações, métodos e ferramentas que buscam disseminar e articular práticas voltadas à mediação de conflitos no ambiente escolar, à integração escola e todo o sistema de garantia dos direitos das crianças e dos adolescentes, e à proteção da comunidade escolar e patrimônio público. Trata-se de uma proposta recente do governo do Estado de São Paulo, entretanto, sendo a escola composta por uma rica diversidade e sendo os conflitos inerentes à condição humana em sociedade, tal fenômeno já se fazia presente há bastante tempo neste cenário (SÃO PAULO, 2012).

Para tanto, o SPEC introduz o Professor Mediador Escolar e Comunitário (PMEC) na instituição escolar, podendo haver até dois docentes na escola para realizar as atribuições desse cargo, almejando o aprimoramento do Sistema de Proteção Escolar. De acordo com o Artigo $10^{\circ}$ da Resolução SE nº7, as atribuições do PMEC consistem em:

I - adotar práticas de mediação de conflitos no ambiente escolar e apoiar o desenvolvimento de ações e programas de Justiça Restaurativa;

II - orientar os pais dos alunos, ou responsáveis, sobre o papel da família no processo educativo;

III - analisar os fatores de vulnerabilidade e de risco a que possam estar expostos os alunos;

IV - orientar a família, ou responsáveis, quanto à procura de serviços de proteção social;

$\mathrm{V}$ - identificar e sugerir atividades pedagógicas complementares a serem realizadas pelos alunos fora do período letivo;

VI - orientar e apoiar os alunos na prática de seus estudos (SÃO PAULO, $2012, \mathrm{~s} / \mathrm{p})$.

É de fácil percepção que o trabalho do PMEC é abarcante e, embora o PMEC conte com a participação obrigatória em cursos e capacitações, este se percebe em um cenário que lhe é comum, mas frente à proposta por uma atuação inovadora. Pode-se observar que as próprias notícias, que saem na mídia institucional sobre o trabalho e a capacitação dos PMECs, já trazem um olhar enviesado, como, por exemplo: "As escolas estaduais de São Paulo já têm quase três mil educadores capacitados para prevenir conflitos" (SÃO PAULO, 2013, s/p). Se o conflito é inerente à condição humana, em sociedade, a partir da diversidade que apreende, como preveni-lo? Tal ideia ainda apresenta o conflito enquanto algo ruim, a ser evitado. Assim, o conhecimento prático desse profissional decorrerá de um manejo próprio, visando atender aos encargos de sua função.

Enfocando os projetos pedagógicos das escolas, Vinha e Tognetta (2009) afirmam que o desenvolvimento da autonomia e de relações mais respeitosas e solidárias são algumas das metas encontradas na maioria desses projetos, no entanto, apesar de buscarem tais objetivos, muitos não sabem ao certo como proceder de forma favorável a isto. 
Sendo assim, o sujeito, com o qual se almeja contribuir na formação, é aquele capaz de articular, de forma crítica e ativa, vontade subjetiva (individual e pessoal) e vontade objetiva (instituições sociais e cultura), refletindo, questionando, construindo e reconstruindo ativamente as mudanças; que viva nos planos individual e coletivo, influenciando e sendo influenciado pelo meio (DIAS, 2005).

Contudo, deve-se considerar que os alunos trazem valores e princípios previamente adotados, os quais serão ativamente construídos e reconstruídos também no âmbito escolar, num jogo de interação constante com semelhantes. Assim, o trabalho com a mediação de conflitos pode ser uma ponte que liga escola e comunidade no objetivo de formar cidadãos autônomos, que refletem sobre a diversidade de valores e participam da construção do bem comum.

Frente a isso, o PMEC terá um papel peculiar no ambiente escolar, lançando mão de estratégias pautadas na Justiça Restaurativa, compreendendo que é possível algum desenvolvimento após a ocorrência de conflitos. Para tanto, o mediador deverá criar condições para que as pessoas em conflito pensem em soluções que sejam boas para ambas as partes.

Todavia, o que se faz possível observar ${ }^{1}$ no cotidiano escolar é um trabalho com base em normas e regras pré-estabelecidas, muitas vezes, utilizadas para a contenção dos alunos, por exemplo: Você não pode usar boné porque é regra da escola!; Não deve agredir o colega porque é errado! Mas, o que aprendem os alunos com essas punições? É possível que eles diminuam essas ações, mas em função de quê? Assim, quando o PMEC intervém, no sentido de impor soluções, ressaltando que alguns conflitos não devam ocorrer apenas porque transgridam regras da escola, não está incentivando o pensamento do aluno sobre os princípios que respaldam tal regra. Por essa razão, se faz importante a compreensão de que o valor moral de uma ação não está na mera obediência às regras determinadas socialmente, mas, sim, no princípio inerente a cada ação (VINHA; TOGNETTA, 2009).

A seriedade da questão pode ser articulada a partir de Piaget (1994, p.23), entendendo que:

[...] as regras morais, que a criança aprende a respeitar, lhe são transmitidas pela maioria dos adultos, isto é, ela as recebe já elaborada, e, quase sempre, nunca elaboradas na medida de suas necessidades e de seu interesse, mas de uma vez só e pela sucessão ininterrupta das gerações adultas anteriores.

O autor pontua que a criança, não participando da elaboração das regras, pode vir a não identificar, nestas, suas necessidades e interesses, o que pode implicar na falta de sentido

\footnotetext{
${ }^{1}$ Faz-se importante esclarecer que uma das autoras, na ocasião da pesquisa, ocupava o cargo de Agente de Organização Escolar em uma escola estadual.
} 
em respeitá-las. A escola tende a adotar práticas pautadas em normativas no intuito de facilitar o processo educativo, no entanto, é preciso refletir acerca do que é compreendido pelo aluno quando respeita - ou não - uma regra, quais motivos e princípios sustenta. Considerando, também, o quanto e como o aluno compreende, já que este não fez parte da elaboração das mesmas.

É necessário que as crianças assimilem os porquês existentes por trás das regras, o que acontece a partir da interferência do adulto, em que tal processo intervirá nas razões pelas quais as normas serão legitimadas (VINHA; TOGNETTA, 2009). Pensando essa interferência como facilitadora da aprendizagem de princípios, na atuação do PMEC, o mediador terá a possibilidade de criar condições para que os envolvidos no conflito problematizem, de forma crítica, em que implica a transgressão de regras da escola; não apenas atendo-se ao não pode porque é regra da escola.

A criança pequena ainda não compreende o sentido das regras, mas as obedece porque respeita a fonte delas (os pais e as pessoas significativas para ela). Além do amor que a leva a querer obedecer às ordens, a criança teme a própria autoridade em si, teme ainda a perda do afeto, da proteção, da confiança das pessoas que a amam. Há também o medo do castigo, da censura e de perder o cuidado. Nessa fase o controle é essencialmente externo. Há, portanto, uma aceitação de regras que são exteriores ao sujeito. $\mathrm{O}$ desenvolvimento moral foi bem sucedido quando, com o tempo, esse controle vai se tornando interno, isto é, um autocontrole, uma obediência às normas que não depende mais do olhar dos adultos ou de outras pessoas. É a moral autônoma (VINHA; TOGNETTA, 2009, p. 528).

Assim, o aluno tende a obedecer às regras, primeiramente, a partir da orientação de outrem, como parte da moral heterônoma, mas com o desenvolvimento da moral autônoma, “[...] não somente tal obediência é apenas parte da moral como deixa de ser seu fundamento, que passa a ser a reciprocidade, o contrato, o projeto comum" (LA TAILLE, 2010a, p. 71). O processo de interiorização pode ser facilitado a partir da atuação do PMEC, intervindo de forma a criar condições para que as pessoas envolvidas no conflito entrem em contato com a visão do outro, com a ideia de diversidade, tal qual com a consequência de seus atos.

Todavia, o que se observa comumente, são atos que tendem à punição como forma de extinguir possíveis conflitos. Ao voltar-se o pensamento para o ato punitivo, considerando a forma como o adulto estabelece a tentativa para que a criança compreenda a importância em não se cometer atos que violem regras pré-estabelecidas pela escola, entende-se, a partir de Piaget (1994, p. 222) que “[...] a punição só é considerada 'justa' na medida em que existem o sentimento de autoridade e o remorso de ter ofendido a autoridade".

Nesse sentido, Piaget (1994, p.156) explicita o sentimento de justiça, ponderando ideias a partir dos contatos que as crianças estabelecem entre si, logo, o sentimento de justiça "embora podendo naturalmente ser reforçado pelos preceitos e exemplo prático do adulto - 
[...] não requer, para se desenvolver, senão o respeito mútuo e a solidariedade entre as crianças".

Ainda enfocando o uso de punições, pode-se citar a atribuição de suspensões ou a redação de ocorrências a serem assinadas pelos alunos. Sobre essa questão, Vinha (1999) aponta que tal imposição tira a oportunidade de o aluno entrar em contato com as consequências naturais dos seus atos. A autora complementa que, se a instituição tem a concepção do conflito voltada para a aprendizagem, este poderá ser trabalhado de forma que o aluno assuma seu ato, pois o conflito pertence aos envolvidos e tal atitude é saudável e constituinte da formação do ser humano.

Em concordância, Durkheim (2008, p. 236) afirma que, quando numa sala de aula a justiça acontece a partir apenas do professor, desconsiderando a opinião comum, "parecerá uma sociedade na qual os magistrados editam penas contra atos que não são condenados pelo sentimento público". Expandindo a reflexão, é possível perceber a importância do fazer-se neutro ao atuar no processo de mediação, entendendo que o conflito pertence aos envolvidos e, logo, deve ser aberto espaço para que estes tenham a possibilidade de refletir e deliberar sobre as opções cabíveis ou não.

De acordo com La Taille (1992, p.70), "o sujeito autônomo não é um 'reprimido', mas sim um homem livre, pois livremente convencido de que o respeito mútuo é bom e legítimo". Em contrapartida, uma instituição que não considera a existência de conflitos como demanda para intervenção educativa abre possibilidade para atitudes violentas. A ideia dimensional desse fenômeno aponta para algo maior, que vai além da escola e deve ser estimada, a escola integrando a comunidade pode, também, contar com outros atores sociais para participarem dessa mudança, como a família, por exemplo. Família e comunidade, caminhando junto à escola, podem contribuir para com objetivos em comum com a mediação de conflitos.

Por derradeiro, frente a tais atribuições, a proposta, por uma mediação de conflitos, pode contribuir com uma aprendizagem que parte da reorientação das relações sociais, trabalhando aspectos de cooperação, solidariedade, responsabilidade, iniciativa, respeito às diferenças individuais e grupais, como também vir a contribuir com atitudes pautadas na cultura do diálogo. Assim, a partir de tais preceitos, esta pesquisa objetivou refletir sobre a possibilidade do trabalho com a mediação de conflitos na escola auxiliar o desenvolvimento moral dos alunos.

\section{Resultados e Discussão}

No intuito de elaborar a pesquisa de campo, foram contatadas duas instituições de ensino estaduais de uma cidade de pequeno porte do interior de São Paulo, nas quais estava sendo implementado o projeto de mediação de conflitos com o professor mediador escolar e comunitário. A população foi composta por oito participantes, sendo duas professoras mediadoras escolares e comunitárias (uma de cada instituição), duas professoras efetivas que integram o quadro do magistério público (uma de cada instituição) e quatro alunos (sendo 
dois de cada instituição), todos os participantes estão referenciados com nomes fictícios. Os critérios para escolha envolveram a seleção das PMECs, a partir do contato e aceite das instituições nas quais cada uma atuava, a seleção de professores efetivos, compreendendo ativa participação no processo de mediação, sendo indicações das PMECs, como também a escolha dos alunos, contemplando indicações das PMECs acerca daqueles que mais participaram do processo de mediação. Enquanto instrumento, foram utilizados: declarações de consentimento, roteiros de entrevistas (não padronizados e semiestruturados) e gravador.

Para discutir e refletir os resultados obtidos com as entrevistas da presente pesquisa, fez-se uso da Análise de Conteúdo. Elucida-se que tal análise acontece com o intuito de "[...] atender aos objetivos da pesquisa e para comparar e confrontar dados e provas com o objetivo de confirmar ou rejeitar a(s) hipótese(s) ou os pressupostos da pesquisa" (SILVA; MENEZES, 2001, p.35). Dessa forma, foram utilizadas categorias apriorísticas de análise, envolvendo a abrangência de eixos norteadores pré-estabelecidos nos roteiros de entrevista.

Assim, a análise dos resultados está organizada de modo a enfocar as seguintes categorias: concepção de mediação de conflitos, estratégias utilizadas e contribuições advindas do processo de mediação, respectivamente.

\subsection{Concepção de Mediação de Conflitos}

A primeira categoria em análise enfoca a compreensão dos participantes sobre mediação de conflitos. O primeiro aspecto a ser apresentado, enquanto resultado, aponta para a leitura que alunos, professores e PMECs fazem do que vem a ser um conflito. Através das entrevistas, pôde ser observado que os alunos relacionam conflitos a brigas e discussões, "Acho que tem a ver com um grupo de pessoas, porque acontece uma briga..." (fala da aluna Daniela). Como também aparece no relato do aluno Gustavo: "Conflito? É tipo de uma briga, ah, porque tem gente que mexe com os outros, provoca".

As professoras efetivas concordam que o conflito se relaciona com a divergência de opiniões, como aparece na fala da professora Angela: “Conflito é quando há uma diferença de opiniões, em que você não concorda com algo, acho que é isso, são divergências nas opiniões".

Uma das PMECs entrevistada, Cibele, tem uma opinião equivalente à da professora Angela, já a outra PMEC, Cristina, aponta que o conflito refere-se a algo inerente à vida, que diz respeito a um acontecimento que, ao passar de um momento verbal, resulta em uma briga e, por isso, deve ser quebrado. Faz-se importante refletir que os conflitos não são bons nem ruins, tal qualificação é decorrente da forma como se lida com eles. É possível, qualificando os conflitos como ruins, inferir sobre a necessidade de este ser quebrado, comprometendo-se o contato dos indivíduos envolvidos com a complexidade da questão social.

É de suma relevância entender como os conflitos são vistos pelos integrantes da comunidade escolar para pensar, a partir disso, sobre a existência de possibilidades para se 
lidar de forma construtiva com o fenômeno. De acordo com Chrispino (2007), é comum que o conflito apenas seja percebido ao produzir manifestações violentas e, sobre isto, conclui que se houve tal manifestação é porque o conflito já existia na forma de divergência, porém, não houve preparo para que esta fosse identificada.

Por conseguinte, apresenta-se o segundo aspecto analisado: o que os participantes entendem por mediação de conflitos. Os alunos apresentam opiniões semelhantes sobre a compreensão do processo de mediação, apontando que mediar implica em conversar, visando eliminar brigas atuais e futuras. A aluna Patrícia elucida a compreensão de que a mediação "Serve pra ajudar as pessoas, pra que não tenha briga, pra que as pessoas conversem". Já a professora Carolina reflete que:

[...] o objetivo da mediação é sempre o de buscar uma solução pacífica, tentando amenizar, ou mesmo eliminar, os conflitos através do diálogo entre as partes, ela vai fazer com que as partes exponham seus lados e entrem num acordo que não prejudique ninguém, acredito.

Essa professora avalia o objetivo da mediação sem revelar claramente o fator social, mas considerando-o. Promovendo o diálogo e considerando os motivos que os envolvidos defendem, abre-se uma possibilidade para o desenvolvimento moral, pois, a PMEC pode, nesse momento, trabalhar o respeito à diversidade e, frente a isso, a importância da cooperação. Piaget (1994, p. 112) enfatiza que "a consideração das intenções supõe, assim, a cooperação e o respeito mútuo". Para o autor, faz parte do hábito do aluno agir de acordo com os adultos que são importantes para si; e será, quando o aluno procurar agradar ao invés de obedecer, que estará começando a fazer julgamentos, ponderando suas intenções.

Sobre o entendimento do que vem a ser a mediação de conflitos, as PMECs enaltecem que se refere ao trabalho de colocar os envolvidos para conversarem. Contudo, as mesmas divergem no entendimento para além desse fator, como também no que acreditam que seja o objetivo da mediação. A PMEC Cibele demonstra a preocupação com o convívio, almejando que haja um convívio no qual todos tenham a oportunidade de se expressar. Percebe-se, também, que essa profissional enfatiza um trabalho de mediação que valorize a opinião de todos.

Através do relato da PMEC Cristina, observa-se a visão de que o processo de mediação tende a amenizar o conflito através do desabafo. Essa profissional afirma que, com o diálogo, existe a possibilidade de prevenção:

Duas formas, ou a prevenção do conflito, quando a gente percebe que está tendo um conflito e pode tentar uma intervenção, colocar as duas ou mais pessoas envolvidas juntas pra conversar, pra ver se quebra esse conflito, aí quando isso já passou pra agressão, aí depois que passou para agressão, tem que sentar e conversar, porque falando eles minimizam o conflito, eles 
falando, desabafando, eles não têm mais um conflito [...] nesse desabafo eles já melhoram e não vão partir pra brigar, fazem as pazes.

Essa PMEC elucida que existem duas circunstâncias, quando existe o conflito sem agressão física e quando existe o conflito com agressão física. Entretanto, Cristina acredita que, para ambos os casos, proporcionar que os envolvidos falem ajuda a minimizar o conflito, no caso de um conflito sem agressão física, aborda que esta intervenção pode contribuir, de forma também preventiva, para que o conflito não evolua para a violência. Contudo, o desabafo apresenta satisfação imediata e a aprendizagem que se almeja depende de algo para além desse fator.

Por fim, é possível se afirmar que, sucintamente, os participantes compreendem a mediação de conflitos na escola. No entanto, não têm uma visão definida sobre o caráter dos conflitos, afinal, nas falas, em muitos momentos, pode-se interpretar a ideia de que os conflitos devam ser evitados. Entender que o conflito é parte inerente à vida em sociedade abre possibilidades para se lidar com ele de maneira diferenciada, não buscando evitá-lo, ignorá-lo ou contê-lo, mas buscando possibilidades de aprendizagem, preparando os envolvidos para melhor lidarem com esse fenômeno no decorrer da vida.

\subsection{Conhecimento e entendimento sobre estratégias utilizadas na mediação de conflitos}

A segunda categoria de análise busca verificar qual é a compreensão dos participantes acerca das estratégias utilizadas pela PMEC; conhecer o que comumente é utilizado, enquanto estratégia, para que o trabalho com a mediação proporcione condições para refletir sobre o que se tem alcançado.

Quando questionados sobre a compreensão de qual é o trabalho da PMEC na escola, as alunas de uma mesma escola apresentaram respostas que divergiram no sentido de, por exemplo, Daniela acreditar que a PMEC ajuda os alunos a entenderem os problemas uns dos outros, evitando bagunças maiores, enquanto Patrícia acha que o trabalho da PMEC é de cuidar dos alunos, resolvendo os problemas junto com eles. Nesse aspecto, retoma-se a necessidade pela cautela em definir a quem o conflito pertence, pois, ao resolver o problema pelo aluno, tira-se dele a oportunidade de entrar em contato com as consequências de seus atos, de pensar por si próprio em maneiras de lidar com a situação. A intervenção da PMEC, nesse sentido, deve comprometer-se com o cuidado em criar condições para que os próprios envolvidos pensem em soluções, ponderem as divergências e utilizem-se delas para o próprio desenvolvimento.

Em contrapartida, os alunos da outra escola explanam uma compreensão diferente acerca da atuação da PMEC na escola, Gustavo chega a apontar que: 
A PMEC foi lá na sala porque teve a briga, aí ela foi lá pra que ninguém ficasse provocando os outros [...] Eu não sei o que a PMEC faz mais na escola, ela conversa com os alunos... ela encaminha pra direção dar suspensão, é só isso que eu sei.

Dessa forma, pode-se inferir que a experiência pela qual Gustavo passou permitiu que entendesse que o trabalho da PMEC consiste em certas contenções, como aponta ao dizer que a PMEC interveio em sala de aula para que "ninguém mais se provocasse"; não aparece, nesse ponto, a reflexão acerca do porquê existente por trás dessa regra. A percepção de Marina, da mesma escola, não é muito diferente. Eis sua afirmativa:

\begin{abstract}
A PMEC chama pra conversar, e se for grave ela passa pra inspetora, se for mais grave passa pra Coordenadora e muito grave ela passa pra Diretora. A PMEC chama pra conversar [...] chama os dois [...] aí chama a inspetora e se for bem grave chama o Conselho Tutelar aqui na escola.
\end{abstract}

Tais experiências expõem que a intervenção da PMEC se dá no sentido de conter atitudes que não são aceitas, evitando ou contendo conflitos. Segundo Vinha e Tognetta (2009), esses procedimentos exteriores contribuem para a submissão e obediência acrítica dos alunos, como também, dificultam a compreensão acerca das regras, assim, o aluno pode não construir suas próprias significações referentes aos motivos pelos quais segue as regras morais.

As professoras efetivas relatam compreensões inicialmente semelhantes sobre o trabalho da PMEC. Ambas enfocam que a base do trabalho está no diálogo, objetivando alcançar resoluções a partir dos envolvidos. Entretanto, as professoras conhecem estratégias diferentes. Angela relata que, além de promover o diálogo, a PMEC precisa fazer visitas à família e que, além de buscar essa parceria, também faz um trabalho em conjunto com os demais professores, utilizando-se de Aula de Trabalho Pedagógico Coletivos (ATPCs), por exemplo. Já Carolina sabe que a PMEC se utiliza de rodas de conversa e do círculo restaurativo, o qual retrata uma intervenção na qual todos os envolvidos no conflito, direta ou indiretamente, sentam em círculo e expõem o que entendem pelo conflito e como podem propor resoluções que sejam boas para todos.

Todavia, Carolina cita, também, que: "Acabo tendo contato com a PMEC, de forma direta, quando tenho algum problema em sala de aula porque é neste momento em que converso com a mediadora e ela, prontamente, toma as providências". Sua fala reflete um trabalho fragmentado, infere-se que quando a professora conversa sobre a ocorrência de algum conflito com a PMEC, quem toma as providências de forma isolada é a PMEC, sendo que a professora também pode participar do processo.

Nessa perspectiva, Vinha e Tognetta (2009) refletem que os cursos de formação pouco preparam os professores para lidarem com conflitos e, sem tal preparo, o professor sente-se 
inseguro para lidar com ocorrências. As autoras abordam que estratégias como o círculo restaurativo e a assembleia auxiliam no processo de apropriação das normas e valores, proporcionando o contato com o pensamento do outro e o autoconhecimento, aprendendo formas mais justas para resolução dos conflitos, como também, desenvolvendo a autonomia.

De acordo com a PMEC Cristina, sua função é observar muito os alunos, estar em contato com os professores para obter informações e atuar utilizando o diálogo. Diz que ao identificar que o problema envolve uma sala toda, disponibiliza tempo para que seja feita uma roda de conversa com a sala. Afirma buscar palestras e filmes sobre temas como bullying, homofobia e sexualidade. Mas aponta que "na conversa o objetivo é quebrar o conflito, quando já está instaurado. O objetivo fica na conscientização, na informação". Salienta-se, novamente, que não fica claro se o conflito é, de fato, visto como inerente à vida, como oportunidade para a aprendizagem e desenvolvimento moral. De modo que, quando essa PMEC aponta que o conflito deva ser quebrado, não fica clara a participação ativa do envolvido no processo, enquanto ser pensante, com valores.

Por último, cabe ressaltar que fica em evidência a atuação das PMECs por meio do diálogo, que é a estratégia mais conhecida. Contudo, surgem, a partir das falas das PMECs, principalmente, outras intervenções que contribuam para o trabalho com a mediação, como o círculo restaurativo ou roda de conversa, por exemplo. Faz-se plausível analisar que, na discussão dos resultados, também fica em destaque a questão das punições e sanções, como quando um aluno relata que a PMEC leva para a Direção dar suspensão. A partir da teoria articulada, vale enfatizar que atitudes como esta inibem possibilidades de discernimento dos envolvidos sobre os valores morais das regras que optam por adotar ou não.

\subsection{Compreensão acerca de contribuições advindas do trabalho com a mediação de conflitos}

A terceira e última categoria em análise enfoca o que os participantes compreendem e percebem enquanto contribuições obtidas a partir do trabalho com a mediação de conflitos na escola.

Em princípio, a aluna Daniela afirma que a principal contribuição que percebe é que a PMEC ajuda a educar os alunos, diz ter aprendido, em sua experiência, que as pessoas a respeitam como ela própria as respeita. Aparece, nesse ponto, a questão do respeito mútuo, de uma observação da aluna acerca de aspectos relacionados à cooperação.

No entanto, Gustavo, aluno da outra instituição, expõe atitudes contraditórias, diz ter aprendido, com o processo de mediação, valores como: "amizade, felicidade, não partir para a agressão". Gustavo relata, de forma evidente, aspectos relacionados à contenção que experienciou, ao contrário da aluna da outra escola. Quando questionado sobre como se comporta dentro e fora da escola, ele relata: 
Mas aí se alguém me provoca [dentro da escola] tem que ficar de boa, não provocar também, tem que abaixar a cabeça e ficar quieto, dá vontade de falar também, mas senão dá rolo pra mim, tomar suspensão, chamar a mãe e o pai. Aí fora da escola se alguém provoca eu vou pra cima, ah... deixa de lado o que acontece na escola. [...] o trabalho da PMEC contribui que você tem que ficar quieto e tocar pra frente, não brigar mais.

Marina, que estuda na mesma escola que Gustavo, apresenta sentimentos semelhantes aos de Gustavo:

\begin{abstract}
A PMEC contribui na educação, é que tem muita gente da $6^{\mathrm{a}}$ série em diante que fala muita besteira, palavrão e mentira, ela pode tentar ajudar, conversar e chamar o pai e a mãe junto. [...] A PMEC me ajudou, agora eu mudei muito, assim, se os outros vierem brigar comigo, invés de ficar quieta e ficar na minha, eu vou lá e devolvo o que eles me dão. É assim oh, se ele vem e "dá um" na minha cabeça, eu vou lá e "dou um" na cabeça dele também, de novo, por causa que eu não vou ficar segurando isso por muito tempo. [...] Com a PMEC eu aprendi educação, dar carinho pros amigos e ajudar os outros.
\end{abstract}

Dessa forma, as contribuições que aparecem nas falas desses alunos são extremamente contraditórias, e indicam um discurso que existe apenas na teoria. Logo, não aparece, nos relatos, a compreensão acerca da cooperação. Assim, é provável que não tenham compreendido o porquê de se respeitar a regra para fins de boa convivência. Segundo Vinha e Tognetta (2009, p. 528), "ao relacionarmo-nos uns com os outros, é imprescindível a existência de regras que visam garantir a harmonia do convívio social". As autoras também enaltecem o que acontece na heteronomia quando em contato com regras, o que muito se assemelha ao que os alunos relatam:

$\mathrm{Na}$ heteronomia, a obediência ao princípio ou regra não se mantém, pois depende de fatores exteriores, ou seja, a regulação é externa: em alguns contextos a pessoa segue determinados valores, e em outros não mais os segue. Por exemplo, se a pessoa corre o risco de ser punida não age de determinada forma, se não corre este risco, age (VINHA; TOGNETTA, 2009, p. 529).

A professora Carolina demonstra compreensões acerca do desenvolvimento do respeito nos alunos, assim como, desenvolvimento da autonomia: 
Com esta atuação os alunos são incentivados a conversar e se relacionar bem com todos, podem ver que brigar não leva a nada, ao contrário, só piora 0 problema. Com esta nova forma de ver e trabalhar o conflito na escola, os alunos podem ganhar mais autoestima e, consequentemente, uma autonomia que levarão pra vida adulta. [...] os alunos podem se acostumar com esta outra forma de solução na escola e levar isto pra outros ambientes sociais.

Como cita a professora Carolina, sobre o processo de mediação, existe um ponto no qual culmina a questão do respeito que os alunos desenvolvem por outrem. Esse ponto é a autonomia, entendendo que a moral autônoma "é, entre outras coisas, uma moral da igualdade, da reciprocidade, do respeito mútuo” (LA TAILLE, 2010b, p. 107).

As PMECs apresentam enfoques diferentes, enquanto Cristina ressalta a importância em se resgatar valores, Cibele aborda a questão da prevenção à violência entre suas contribuições.

São vários resultados, caiu o índice de violência, os alunos participam mais, os alunos criam mais, eles se interessam mais pela escola. Contribui pra desenvolver valores sociais, o convívio, as boas maneiras. Está relacionado a aspectos sociais porque o PMEC trabalha com o social, com o convívio, respeitar as diferenças. Autonomia... ah, tivemos muitos casos assim, que começaram a, antes de agredir, começaram a pensar, a vir falar com a gente, antes de existir o conflito (fala da PMEC Cibele).

Aprofundando-se na fala de Cibele, é plausível enaltecer o que ocorre no processo de tornar-se autônomo, entendendo que "o indivíduo que é autônomo segue regras morais que emergem dos sentimentos internos que o obrigam a considerar os outros além de si, havendo a reciprocidade" (VINHA; TOGNETTA, 2009, p. 529). Ademais, mesmo citando que os alunos começaram a pensar, a PMEC Cibele aponta que o aluno começou a procurá-la antes de agredir, tal atitude transparece o quanto a PMEC se torna uma profissional de referência para os alunos. Porém, entender o que fundamenta a atitude dos alunos frente às situações de conflito é essencial para se conhecer a que os alunos respondem, se dominam os princípios inerentes à regra e se autorregulam ou apenas evitam transgredir por medo da contenção. Quando os indivíduos são autônomos, “[...] a fonte das regras não está mais nos outros, na comunidade ou em uma autoridade (como na moral heterônoma), mas no próprio indivíduo (autorregulação)" (VINHA; TOGNETTA, 2009, p. 529).

Já a PMEC Cristina, aborda que:

Vamos tentar resgatar os valores, acho que não é a curto prazo a contribuição da mediação, é a longo prazo, mas acho que é um bom começo, pra resgatar os valores e envolver os pais nisso. Acho que contribui com o lado social, na conscientização, mostrando a diferença, trabalhando o 
respeito, dando espaço e mostrando como podem ser cidadãos melhores, eles não têm mesmo... eles não sabem se portar numa entrevista, precisam desenvolver.

É perceptível que elas relatam, a partir do trabalho com a mediação na escola, contribuições possíveis em aspectos do desenvolvimento moral dos alunos. No entanto, não fica explícito o pensamento que adotam para chegar a tal fim. Com base nessa falta de metodologia, enfoca-se a possibilidade desse fator estar relacionado à falta de habilitação e formação específicas. Sabe-se que as PMECs passam por treinamentos e têm contato com eventos sobre o tema, mas, ainda assim, segundo as participantes, na prática, não existem supervisões ou subsídios aos quais possam recorrer senão à teoria, e isso por conta própria. Entretanto, apesar de a realidade das participantes indicarem essa falta de supervisão, não se pode desconsiderar o que dispõe o artigo $7^{\circ}$ da Resolução SE no 07/2012, bem como o artigo $6^{\circ}$ da Resolução SE n ${ }^{\circ}$ 19/2010 (que institui oficialmente o Sistema de Proteção Escolar na rede) e, ainda, a Resolução $\mathrm{SE} \mathrm{n}^{\circ}$ 54/2013, que altera dispositivos da Resolução SE ${ }^{\circ}$ 07/2012. Considerando essas resoluções, os docentes que atuam como PMEC contam com a formação mensal (oito por ano) e acompanhamento de dois gestores regionais, sendo obrigatoriamente um Supervisor de Ensino. Esses profissionais têm a incumbência legal de selecionar, formar e acompanhar o trabalho dos Professores Mediadores em suas respectivas diretorias de ensino.

Por fim, na análise desta categoria, pode-se constatar o quanto o processo de mediação visa atingir aspectos do desenvolvimento moral, criando condições para formar sujeitos autônomos, que adotem atitudes coerentes com uma convivência harmoniosa e pautada no respeito. Contudo, nem todos demonstraram, de forma clara, o aprendizado obtido a partir do processo de mediação, apresentando relatos contraditórios. As professoras efetivas e PMECs têm clareza do que podem atingir enquanto contribuições, mas, a partir da fala dos alunos, percebem-se percepções diferenciadas sobre a atuação das PMECs: as alunas Daniela e Patrícia reconhecem que a professora tem um trabalho de mediação mais voltado à cooperação; enquanto os alunos Gustavo e Marina identificam uma atitude mais punitiva da PMEC, em vez de adotar estratégias pacíficas e menos individualizadas.

\section{Considerações finais}

Primeiramente, o presente trabalho permitiu observar o quanto é incerta a concepção que alunos, professores e PMECs têm sobre o caráter dos conflitos. Assim, de acordo com a fundamentação teórica e a análise dos resultados, não existe uma frente de atuação que aponte um só posicionamento ao lidar com o fenômeno, no contexto escolar, embora, em várias falas, tenha aparecido que os conflitos são parte inerente à vida.

Foi observado que as escolas, comumente, almejam contribuir para a formação do aluno: autônomo, crítico e ético. Frente a esse dado, buscou-se discutir a compreensão geral 
sobre aspectos do desenvolvimento moral e, posteriormente, a possível articulação destes com o processo de mediação de conflitos feito pelo PMEC. Destarte, aparecem intervenções que visam ignorar ou conter o conflito, utilizando punições e sanções. Assim, não fica clara a visão do como criar condições e, tampouco, o pensamento sobre as implicações das estratégias adotadas. É possível pensar que a lacuna, que aqui se apresenta, possa ser consequência de uma implementação recente e da falta de formação e supervisão específicas, no caso desta amostra, apesar de estas estarem previstas nas resoluções já citadas anteriormente.

A presente pesquisa objetivou discutir e refletir acerca da possibilidade da mediação de conflitos, no contexto escolar, auxiliar o desenvolvimento moral de alunos a partir de uma pesquisa de campo. Foi possível constatar que a mediação de conflitos abre possibilidades para que sejam trabalhados aspectos do desenvolvimento moral, no entanto, a partir da análise da pesquisa de campo, pôde-se perceber o quanto não há clareza sobre como se proceder para atingir tal finalidade.

Por derradeiro, a aprendizagem que advém a partir da conclusão desta pesquisa é a de que pode não ser fácil, assim como não ser imediato, mas os conflitos podem ser construtivos se vislumbrados enquanto possibilidades para o próprio crescimento, amadurecimento pessoal e moral.

\section{Referências}

CHRISPINO, A. Gestão do conflito escolar: da classificação dos conflitos aos modelos de mediação. Ensaio: Avaliação e Políticas Públicas em Educação, Rio de Janeiro, v. 15, n. 54, p. 11-28. Mar. 2007. Disponível em: <http://www.scielo.br/scielo.php?script=sci_arttext\&pid=S0104$40362007000100002 \& \operatorname{lng}=e n \& n r m=i s o>$. Acesso em: 22 Ago. 2013.

DIAS, A. A. Educação moral e autonomia na educação infantil: o que pensam os professores. Psicologia Reflexão e Crítica, Porto Alegre, v. 18, n. 3, p. 370-380. Dez. 2005. Disponível em: <http://www.scielo.br/scielo.php?script=sci_arttext\&pid=S010279722005000300011\&lng=en\&nrm=iso>. Acesso em: 28 Jul. 2012.

DURKHEIM, E. A Educação Moral. Tradução de Raquel Weiss. Petrópolis: Editora Vozes, 2008.

LA TAILLE, Y. A questão da Indisciplina: ética, virtudes e educação. 5 ed. In: DEMO, P.; LA TAILlE, Y; HOFFMANN, J. (Orgs.). Grandes Pensadores em Educação. O desafio da aprendizagem, da formação moral e da avaliação. Porto Alegre: Mediação, 2010a. p. 67-98.

LA TAILLE, Y. Moral e Ética: uma leitura psicológica. Psicologia: Teoria e Pesquisa, Brasília, v. 26, n. spe, p. 105-114. 2010b. Disponível em: 
<http://www.scielo.br/scielo.php?script=sci_arttext\&pid=S0102-

37722010000500009\&lng=en\&nrm=iso>. Acesso em: 11 Jun. 2012.

LA TAILLE, Y. Desenvolvimento do juízo moral e afetividade na teoria de Jean Piaget. In: LA TAILlE, Y.; OLIVEIRA, M. K.; DANTAS, H. (Orgs.). Piaget, Vygotsky e Wallon: teorias psicogenéticas em discussão. São Paulo: Summus, 1992. p. 47-73.

PIAGET, J. O Juízo Moral na Criança. 3 ed. Tradução de Elzon Lenardon. São Paulo: Summus, 1994.

SÃO PAULO [Estado]. Resolução SE-19, de 12 de fevereiro de 2010. Institui o Sistema de Proteção Escolar na rede estadual de ensino de São Paulo e dá providências correlatas. São Paulo, SEE, 2010. Disponível em:

<http://siau.edunet.sp.gov.br/ItemLise/arquivos/07_12.HTM?>. Acesso em: 20 Ago. 2015.

SÃO PAULO [Estado]. Resolução SE-7, de 19 de janeiro de 2012. Dispõe sobre o exercício das atribuições de Professor Mediador Escolar e Comunitário do Sistema de Proteção Escolar, e dá providências. São Paulo, SEE, 2012. Disponível em:

<http://siau.edunet.sp.gov.br/ItemLise/arquivos/07_12.HTM?Time=1/24/2012>. Acesso em: 25 Ago. 2015.

SÃO PAULO [Estado]. Resolução SE-54, de 22 de agosto de 2013. Altera dispositivo da Resolução SE n⿳07/2012 que dispõe sobre o exercício das atribuições de Professor Mediador Escolar e Comunitário do Sistema de Proteção Escolar, e dá providências. São Paulo, SEE, 2013. Disponível em:

<http://siau.edunet.sp.gov.br/ItemLise/arquivos/54_13.HTM?Time=25/08/2015\%2010:31:02 $>$. Acesso em: 25 Ago. 2015.

SÃO PAULO [Estado]. Abertas as inscrições para o curso de Mediação Escolar e Comunitária. Portal de Notícias da Secretaria da Educação do Estado de São Paulo. São Paulo, SEE, 2013. Disponível em: <http://www.educacao.sp.gov.br/noticias/abertas-asinscricoes-para-o-curso-mediacao-escolar-e-comunitaria>. Acesso em: 22 Ago. 2013.

SILVA, E.; MENEZES, E. M. Metodologia da Pesquisa e elaboração de dissertação. 3 ed. Florianópolis: Laboratório de Ensino a Distância da UFSC, 2001.

VINHA, T. P. O Educador e a Moralidade Infantil numa Perspectiva Construtivista. Revista do Cogeime, v. 7, n.14, p. 15-38, Jul. 1999.

VINHA, T. P.; TOGNETTA, L.R.P. Construindo a autonomia moral na escola: os conflitos interpessoais e a aprendizagem dos valores. Revista Diálogo Educacional, Curitiba, v. 9, n. 28, p. 525-540, Dez. 2009. 
Recebido em: 07/01/2014

Revisado em: 19/02/2015

Aprovado para publicação em: 27/04/2015

Publicado em: 31/08/2015 